\title{
Original
}

\section{Promotion of Bone Formation around Alendronate-immobilized Screw-Type Titanium Implants after Implantation into Rat Molar Tooth Sockets}

\author{
Yuki Raita1), Koichiro Komatsu ${ }^{2)}$, Akira Nifuji ${ }^{2)}$, Mitsunobu Sato ${ }^{3)}$, Mitsuhiko Morito ${ }^{4)}$ and Tohru Hayakawa \\ 1) Department of Geriatric Dentistry, Tsurumi University School of Dental Medicine, Yokohama, Japan \\ 2) Department of Pharmacology, Tsurumi University School of Dental Medicine, Yokohama, Japan \\ 3) Division of Liberal Arts, Kogakuin University, Hachioji, Japan. \\ 4) Tsurumi University, Yokohama, Japan \\ ${ }^{5)}$ Department of Dental Engineering, Tsurumi University School of Dental Medicine, Yokohama, Japan \\ (Accepted for publication, January 15, 2014)
}

\begin{abstract}
The aim of this study was to evaluate the effects of alendronate immobilization on bone formation following the implantation of apatite-coated titanium implants in rats. Thin carbonate-containing apatite coatings were deposited onto titanium implants (Ti implants) using a molecular precursor method. Alendronate was then immobilized on apatite-coated titanium implants (HA implants) by immersing the HA implants in alendronate solution (Ald implants). The rat molars were extracted, and the implants were immediately placed in the tooth sockets. Bone labeling was performed 14 and 7 days before sacrifice. At 3 and 9 weeks after implantation, undecalcified sections were prepared and bone histomorphometry was performed. Greater bone mass was found around the Ald implants than around either the Ti or HA implants at both 3 weeks and 9 weeks. At 3 weeks, fluorochrome bone labeling was greater around the Ald implants than around the Ti implants, and the values of bone to implant contact (BIC) and bone mass (BM) were significantly greater around the Ald implants than around the HA and Ti implants. At 9 weeks, bone labeling decreased and the values of BIC and BM increased compared with those at 3 weeks for all types of implant. In conclusion, we found that immobilized alendronate triggered pronounced bone formation around the implants at an early stage of bone healing. These results suggest that alendronate immobilization accelerates implant fixation early in the healing phase.
\end{abstract}

Key words: Bisphosphonate, Titanium implant, Molecular precursor method, Apatite coating, Rat maxilla

\section{Introduction}

Titanium and titanium alloys are widely used as dental and orthopedic implants. Various types of mechanical and chemical surface modification, such as blasting, alkaline treatment and hydroxyapatite coating, have been performed to accelerate and improve the bone healing process. ${ }^{1,2)}$ In addition, the efficacy of surface coating or immobilization with bioactive molecules such as cell adhesive protein has also been reported to enhance cell activities. ${ }^{3,4)}$

Bisphosphonates (BPs) have been widely used for treating several diseases characterized by osteoclast-mediated bone resorption, such as osteoporosis, osteogenesis imperfecta, Paget disease and tumor-associated bone disease. ${ }^{5-7)}$ Although the exact mechanism of action of BPs on bone resorption is unknown, it is generally recognized that binding of the P-C-P to bone is an essential step leading to the suppression of bone resorption induced by osteoclasts. ${ }^{8)}$ After the successful clinical use of BPs without

Correspondence to: Dr. Yuki Raita, Department of Geriatric Dentistry, Tsurumi University School of Dental Medicine, 2-1-3 Tsurumi, Tsurumiku, Yokohama 230-8501, Japan; Tel.: +81 455808409 ; Fax: +81 45 5739599 ; E-mail: raita-yuuki@tsurumi-u.ac.jp nitrogen, such as clodronate or etidronate, more potent antiresorptive nitrogen-containing BPs, such as pamidronate and alendronate, have been developed. ${ }^{9}$ Nitrogen-containing BPs, such as alendronate and risedronate, act on the cholesterol pathway by inhibiting diphosphate synthase in the mevalonate pathway. ${ }^{9-11)}$ In contrast, non-nitrogen BPs such as clodronate and etidronate are transformed metabolically into cytotoxic ATP analogues that inhibit ATP-dependent intracellular enzymes. ${ }^{9,12)}$ As another approach for investigating the bone resorption mechanism of BPs, computational analyses using molecular mechanics and molecular orbital calculations were reported. ${ }^{13)}$ Stable conformations of BP/ $\mathrm{Ca}$ complexes with the lowest steric energies and the reactivity of BPs to calcium were calculated.

Local application of BPs by their immobilization on implant materials has been reported. Some studies to immobilize BP on stainless screws were performed and increases of bone density and/or fixation of stainless screws after their implantation into rat tibiae were reported. ${ }^{14,15)}$ Pamidronate, ibandronate and zoledronate were immobilized onto fibrinogen-coated stainless screws. In contrast, BP is known to have high affinity for apatite 


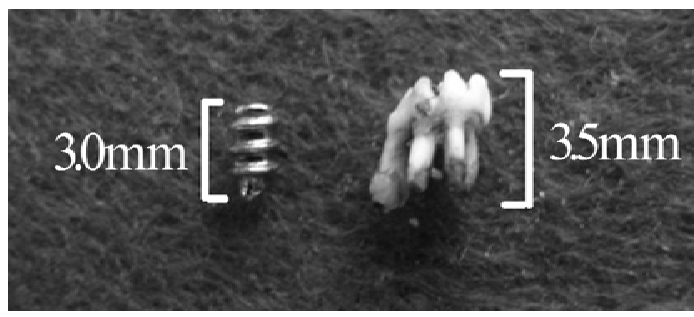

Figure 1. Ti implant used in the present study $(1.5 \mathrm{~mm}$ in diameter, $3.0 \mathrm{~mm}$ in length). Extracted rat molar is also shown.

ceramics. ${ }^{16)}$ Nitrogen-containing BP was immobilized onto apatitecoated titanium implant and bone formation around the rat tibia or canine ulna was evaluated. The immobilization of BP was effective for stimulating new bone formation around the implant and improving bone-implant integration and implant stability after implantation into rat tibiae, that is, cortical bone. ${ }^{17-19)}$ Gao et al. ${ }^{20)}$ evaluated the bone response to surface-immobilized BPs on apatite-coated titanium implants in tibiae of ovariectomized rats, namely, an osteoporotic model. Immobilization of three different BPs triggered pronounced bone-implant integration and early bone formation around the implants.

It is suggested that the bone responses of long bones such as the tibia or the femur differ from those of mandibles and the maxilla. ${ }^{21,22)}$ Some researchers reported the promotion of osteogenesis around BPs immobilized on titanium implants in the mandibular molar or premolar region of dogs. ${ }^{23,24)}$ Animal experiments using rats were also reported. Titanium implants were placed in the upper molar socket after one month and the mechanism of osseointegration was investigated. ${ }^{25)}$ The ultrastructure of the peri-implant epithelium-titanium implant interface was also clarified by using rat maxilla implantation. ${ }^{26}$ ) Komatsu et al. ${ }^{27)}$ treated the roots of extracted teeth of rat maxilla with alendronate and then replanted them into the sockets. They found that alendronate treatment effectively inhibited root and bone resorption and stimulated bone formation around alendronate-treated replanted rat teeth.

In the present study, we established an immediate loading model of titanium implants using rats and evaluated the bone response to alendronate-immobilized screw-type titanium implants after immediate implantation in the rat maxilla region. Alendronate was immobilized on apatite-coated screw-type titanium implants, the coating of which was performed using the molecular precursor method. $^{28)}$

\section{Materialas and Methods Apatite coating onto titanium implant}

Casted titanium implants (Ti, 99.8 mass \%, APEX Co., Tokyo, Japan), measuring $1.5 \mathrm{~mm}$ in diameter and $3.0 \mathrm{~mm}$ in length, screw type, were used. The diameter and length of the titanium screw implants were set by comparison with those of the extracted rat

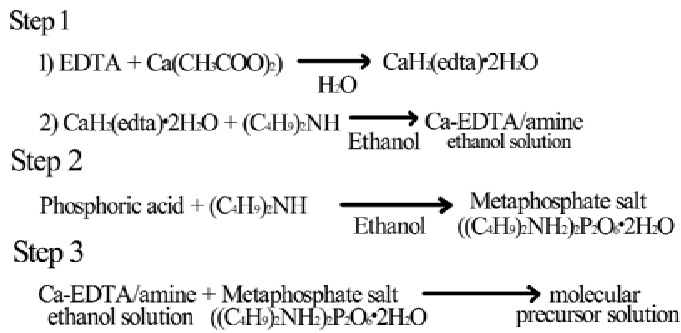

Figure 2. Schematic presentation of the preparation of the molecular precursor solution.

tooth, as shown in Fig. 1.

Apatite coating was performed according to a previously described method. ${ }^{28)}$ The general procedure for the preparation of molecular precursor solution is shown in Fig. 2. The preparation mainly consisted of 3 steps: (1) preparation of calciumethylenediaminetetraacetic acid (CA-EDTA) ethanol solution, (2) preparation of dibutylammonium diphosphate salt $\left.\left(\left(\mathrm{C}_{4} \mathrm{H}_{9}\right)_{2} \mathrm{NH}_{2}\right)_{2} \mathrm{P}_{2} \mathrm{O}_{6} \cdot 2 \mathrm{H}_{2} \mathrm{O}\right)$, and (3) addition of dibutylammonium diphosphate salt into $\mathrm{Ca}-\mathrm{EDTA} / \mathrm{amine}$ ethanol solution by adjusting the $\mathrm{Ca} / \mathrm{P}$ ratio to 1.67 .

Subsequently, Ti implant was immersed in the molecular precursor solution $(\mathrm{Ca}$ ion concentration $=0.157 \mathrm{mmol} / \mathrm{g}$ ) for 20 min. Then, the treated Ti implant was heated at $600{ }^{\circ} \mathrm{C}$ for $2 \mathrm{hr}$ using a tubular furnace (EP-KRO-12K, Isuzu Seisakusho, Co., Ltd., Tokyo, Japan) under oxygen gas introduction at a rate of $100 \mathrm{ml} / \mathrm{min}^{29)}$ Thin apatite film was deposited on the Ti implant surface and then apatite-coated titanium (HA) implant could be obtained.

\section{EPMA analysis}

Apatite coating of the Ti implant was confirmed by electron probe micro-analysis (EPMA, JXA-8900R, JEOL Ltd., Tokyo, Japan) at an accelerating voltage of $20 \mathrm{kV}$ by detecting the X-ray intensities of $\mathrm{Ca}-\mathrm{K} \alpha$ and $\mathrm{P}-\mathrm{K} \alpha$. The specimens were embedded in epoxy resin. After curing the resin, the specimens were cut vertically through the middle using a cutting machine to observe the surface of the HA implant. Then, carbon was coated onto the specimens before the EPMA analysis. The presence of apatite coating was confirmed by element mapping of calcium and phosphorus.

\section{Immobilization of alendronate onto hydroxyapatite}

The apatite-coated titanium implants were immersed in a solution of $10^{-2} \mathrm{M}$ disodium 4-amino-1-hydroxybutylidene-1,1bisphosphonate (alendronate sodium, LKT Laboratories, Inc., USA) for $24 \mathrm{~h}$ at $37^{\circ} \mathrm{C}$, and then dried at room temperature in a desiccator. ${ }^{16)}$ Alendronate is nitrogen-containing bisphosphonate. Finally, alendronate-immobilized (Ald) implants could be obtained. 
Yuki Raita et al.: Bone Formation around Alendronate-Immobilized Titanium Implant
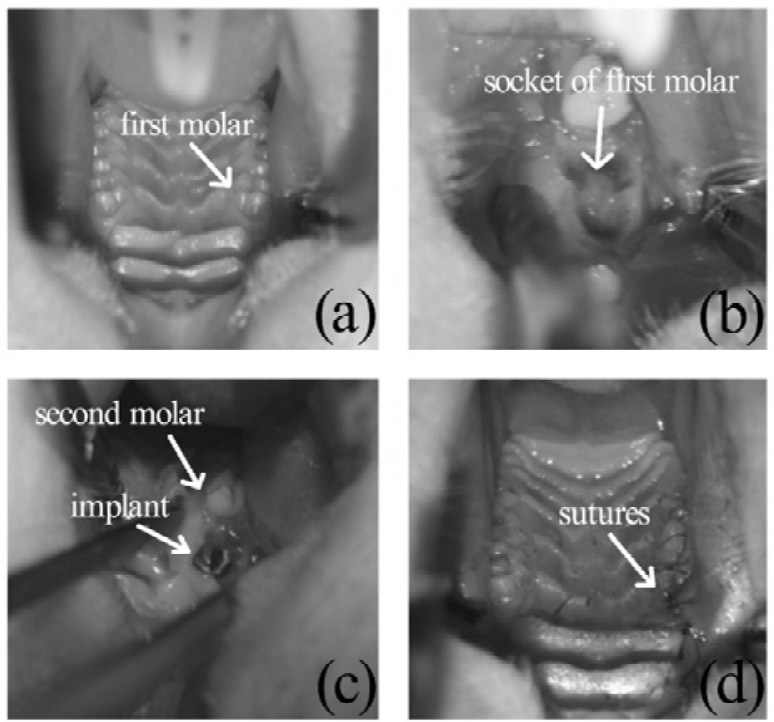

Figure 3. Procedures for implantation into the root sockets of rat maxillary molar: (a) before extraction, (b) after extraction. Socket of the first molar could be seen: (c) after implantation, (d) after suturing.

Alendronate immobilization was confirmed by X-ray photoelectron spectroscopy (XPS, ESCA-3400, $20 \mathrm{~mA}, 10 \mathrm{kV}$, Shimadzu, Tokyo, Japan). N1s and P2p spectra, which were derived from the structure of alendronate, were evaluated. The binding energy of each of the spectra was calibrated with $\mathrm{C} 1 \mathrm{~s}$ of $284.8 \mathrm{eV}$.

\section{Surface observation by scanning electron microscopy}

The surface of each implant, that is, Ti, HA and Ald implants, was observed by scanning electron microscopy (SEM, JSM$5600 \mathrm{LV}$, JEOL, Tokyo, Japan) at an accelerating voltage of 15 $\mathrm{kV}$. HA and Ald samples were coated with gold before SEM observation.

The surface roughness (RA) of Ti, HA and Ald implants was measured with a Handysurf E-30A (Tokyo Seimitsu, Tokyo, Japan) with a scan length of $4 \mathrm{~mm}$ and a cut-off value of 0.8 .

\section{Experimental design and implantation procedure}

Animal experiments were reviewed and approved by the Institutional Animal Care Committee of Tsurumi University School of Dental Medicine (Certificate Number: 12042). A total of eighteen male Wistar rats with a weight of approximately $180 \mathrm{~g}$ (6 weeks old) were used. The rats were housed two per cage at $20-25{ }^{\circ} \mathrm{C}$ in a $12 \mathrm{~h}$ circadian light rhythm and fed a powdered diet and tap water ad libitum during the experimental period.

Each animal received one implant. A total of eighteen implants were inserted, namely, three Ti, three HA and three Ald implants for 3 weeks implantation, and three Ti, three HA and three Ald implants for 9 weeks implantation. Before surgery, all Ti, HA and Ald implants were sterilized in an autoclave.
A procedure for the animal experiments is shown in Fig. 3. Surgical interventions were conducted under general anesthesia by intraperitoneal injection of ketamine hydrochloride $(47 \mathrm{mg} /$ $\mathrm{kg}$ ) and medetomidine hydrochloride $(0.4 \mathrm{mg} / \mathrm{kg})$. The maxillary first molar on the right side was extracted using forceps (Fig. 3a). After the incision of periodontal tissue, sockets of the mesial roots of the molar on the right side were enlarged with a dental reamer (\#90-\#140, Fig. 3b). ${ }^{30)}$ The implant was fixed into the prepared root socket using a screwdriver (Fig. 3c). Incisions of the periodontal tissue were closed with 7-0 polyamide non-resorbable sutures (Fig. 3d, BioFit-D, WASHIESU, Tokyo, Japan). After the operation, the rats were injected subcutaneously with benzyl penicillin $\mathrm{G}$ procaine $(3,000,000 \mathrm{U} / \mathrm{kg})$ and were awakened with an intraperitoneal injection of atipamezole hydrochloride $(0.83$ $\mathrm{mg} / \mathrm{kg}$ ). The sutures were removed 2 days after surgery.

After the implantation, the rats were subcutaneously injected with two kinds of fluorochrome labeling compound, alizarin red (15 mg/kg, Wako Pure Chemical Industries, Ltd., Osaka), 14 days before sacrifice, and calcein $(5 \mathrm{mg} / \mathrm{kg}$, Wako Pure Chemical Industries, Ltd.), 7 days before sacrifice, for the monitoring of new bone formation. Fluorescent dyes chelate to calcium ions, resulting in deposition of a multiple vital label on all actively mineralizing bone surfaces. ${ }^{30)}$

The rats were euthanized 21 days and 63 days after implantation by an overdose of diethyl ether and then maxillae were harvested. Each implant site, including the implant and the soft and hard peri-implant tissues, was dissected using a diamond saw (Cutting Grinding System, BS-300CP band system, EXAKT, Apparatebau GmbH \& Co., KG, Norderstedt, Germany).

\section{Micro-computed tomography and confocal laser scanning microscopy observation}

Specimens including the maxilla were fixed in $10 \%$ neutral buffered formalin for 7 days. Then, the specimens were dehydrated through a graded series of ethanol: $70 \%, 80 \%, 90 \%, 96 \%$ and $100 \%$, and embedded in methylmethacrylate resin.

Before resin embedding, each maxilla containing the implant was horizontally scanned at $60-\mu \mathrm{m}$ intervals with a microcomputed tomography system (Micro-CT, Latheta, Aloka, Tokyo, Japan) to confirm the placement of the implant into the maxillary bone. The tube voltage was $50 \mathrm{kV}$ and the tube current was $1 \mathrm{~mA}$.

After polymerization, non-decalcified sections were prepared using a cutting-grinding technique (EXAKT-Cutting Grinding System, BS-300Cp band system and $400 \mathrm{CS}$ micro grinding system, EXAKT) ${ }^{31)}$ Sections of approximately $50-70 \mu \mathrm{m}$ thickness were obtained.

Before staining the sections, a confocal laser scanning microscopy (CLSM, TCS Multi-Photon, Leica, Germany) photograph was taken. As alizarin red labeling was indistinct in this study, calcein labeling was used for the quantitation of new 


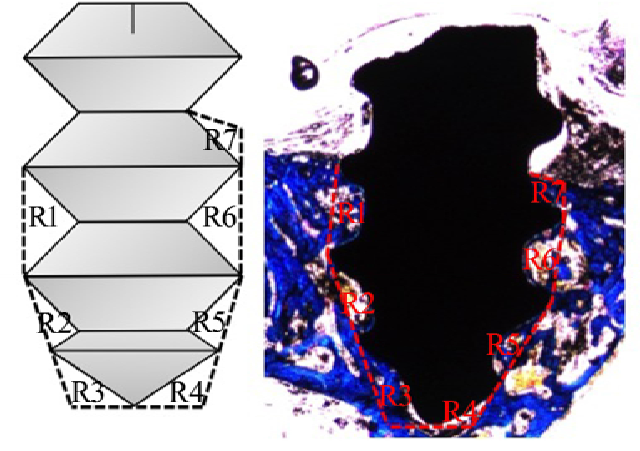

Figure 4. Illustration of the region of interest (ROI) for histomorphometric analysis.

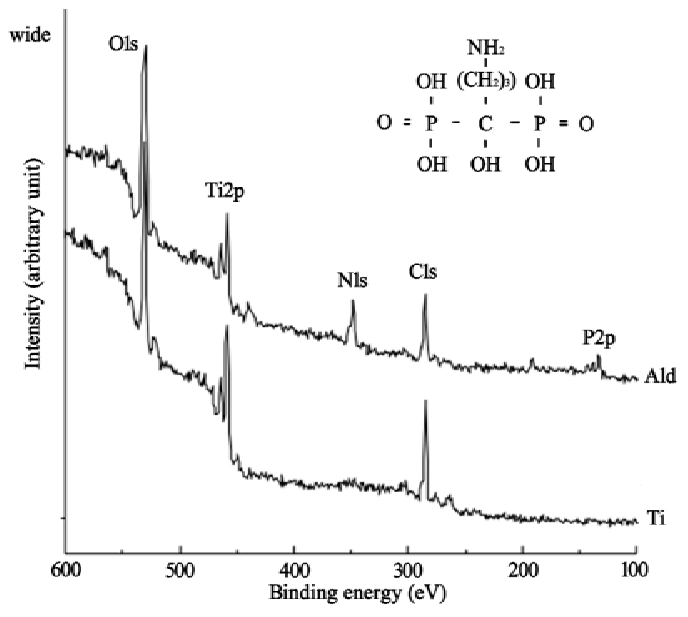

Figure 6. XPS spectra of Ti and Ald implants.

bone formation. ROIs (regions of interest) were determined as the total of both mesial and distal triangular areas formed by the threads, as illustrated in Fig. 4. A triangular area was sometimes partly embedded by new bone, like R7. In such cases, R7 was included in the total area of the ROI. New bone formation around the implants was evaluated as the total length of calcein labeling ${ }^{32)}$ per total area of ROI on the CLSM images using an image analysis system (WinROOF, Visual System Division, Mitani Corporation, Tokyo, Japan).

\section{Histological preparation and evaluation}

The central most ground section of each implant was chosen for morphologic and morphometric assessment. After CLSM, surface staining of the undecalcified sections with methylene blue and basic fuchsin was performed. The interface and the surrounding bone tissue were observed using light microscopy (BX51, OLYMPUS, Tokyo, Japan, magnification 200×)

Bone to implant contact (BIC) was defined as the percent of direct bone contact to the total perimeter of the screw implant in the ROI area. Bone mass (BM) was evaluated as the percentage of bone volume in the ROI area, ${ }^{32)}$ as illustrated in Fig. 4. Both measurements were carried out for the medial and distal sides
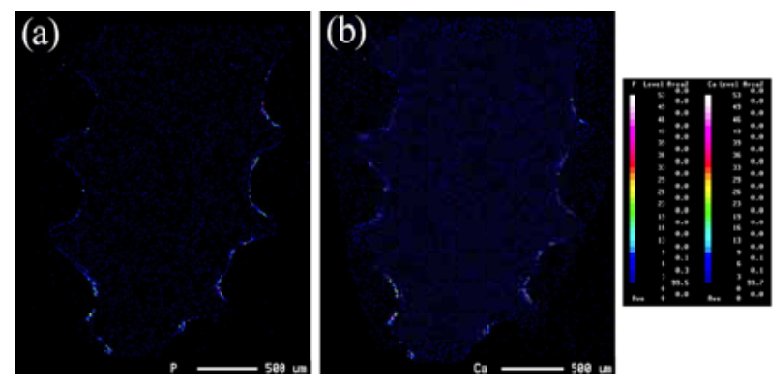

Figure 5. EPMA analysis of the surface area of the HA implant: (a) phosphate mapping, (b) calcium mapping.
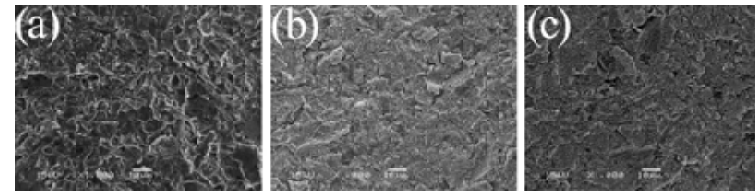

Figure 7. SEM observation of the surface of the implants employed in the present study: (a) Ti implant, (b) HA implant, (c) Ald implant.
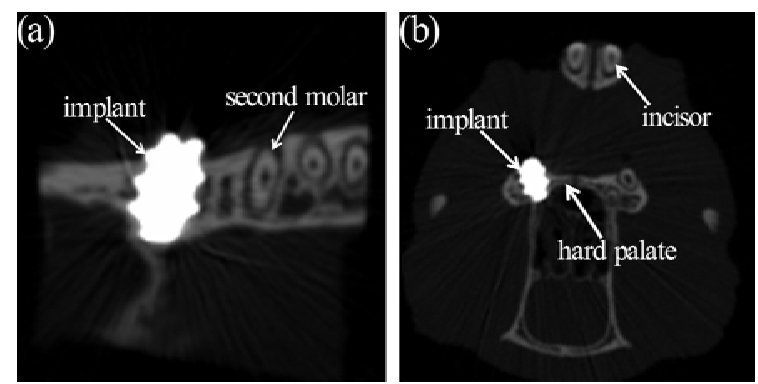

Figure 8. Micro-Ct appearances after the implantation into the extracted socket of rat first maxillary molar.

using the image analysis system.

\section{Statistical analysis}

The quantitative data were statistically analyzed across the three implant groups using one-way analysis of variance (ANOVA) with StatView 5.0 (HULINKS, Tokyo, Japan). Bonferroni post hoc test was further used to probe the pairwise comparisons. To compare the data at 3 weeks and 9 weeks for each implant group, we used non-paired $t$-test. $P$ values of less than 0.05 were considered significant and the data are expressed as the mean \pm standard deviation (SD).

\section{Results}

\section{Surface characterization}

Apatite coating was identified by EPMA mapping and alendronate immobilization was characterized by XPS measurement. Fig. 5 shows the EPMA elemental color mapping images of $\mathrm{Ca}$ and $\mathrm{P}$ on the surfaces of Ti and HA implants. $\mathrm{Ca}$ and $\mathrm{P}$ derived from coated apatite were clearly present on the HA 
Yuki Raita et al.: Bone Formation around Alendronate-Immobilized Titanium Implant
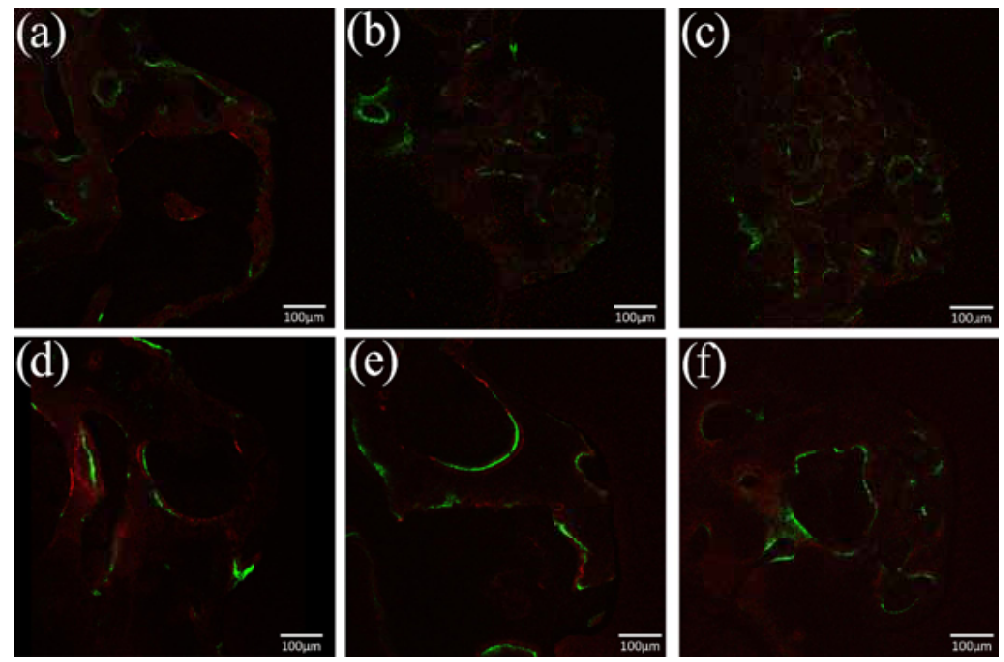

Figure 9. Fluorescence microscopic images with labeling of alizarin red and calcein.

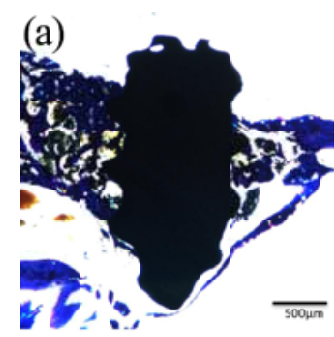

(b)
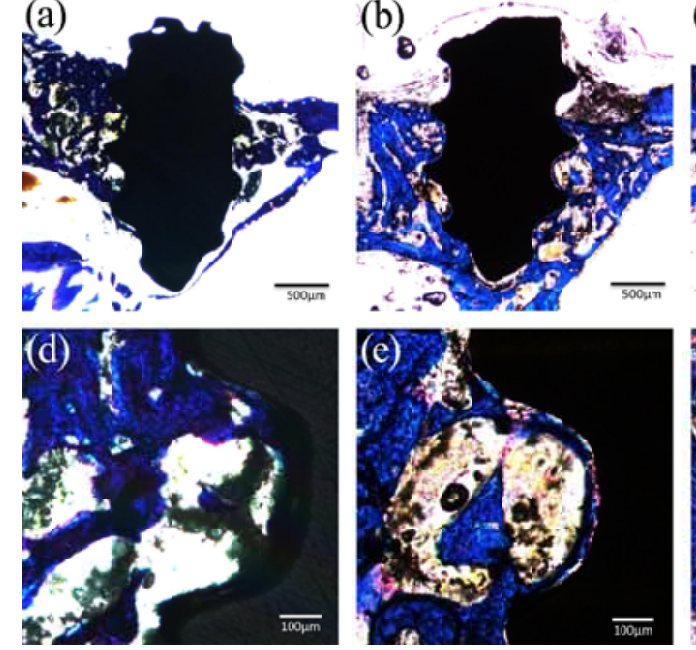

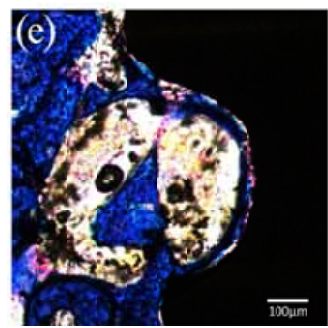

(c)
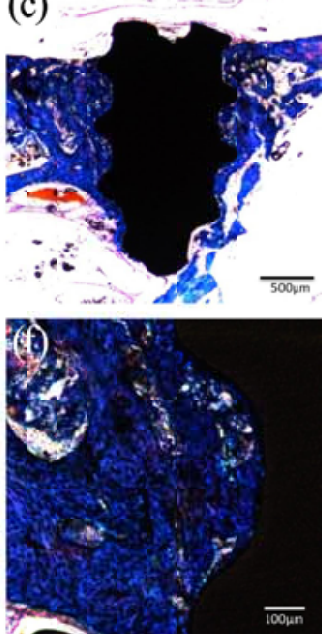

Figure 10. Histological appearances of Ti, HA and Ald implants after 3 weeks of implantation (Ti implant (a), HA implant (b), Ald implant (c), Ti implant (d), HA implant (e), Ald implant (f)).
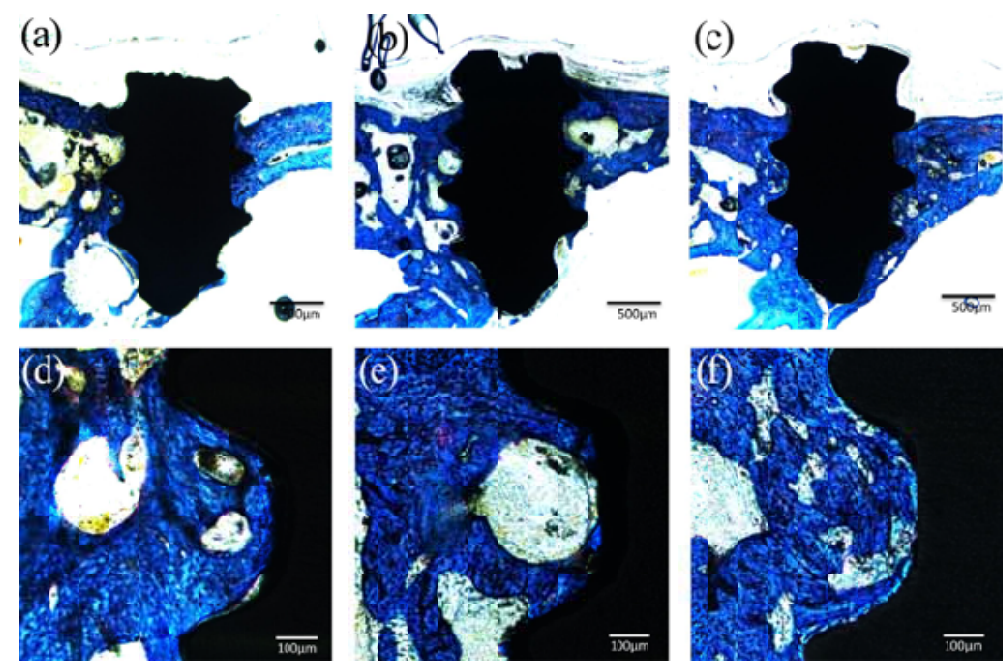

Figure 11. Histological appearances of Ti, HA and Ald implants after 12 weeks of implantation (Ti implant (a), HA implant (b), Ald implant (c), Ti implant (d), HA implant (e), Ald implant (f)). 
J.Hard Tissue Biology Vol. 23(2):177-186, 2014

Table 1 Measured Surface roughness $(\mu \mathrm{m})$

\begin{tabular}{cc}
\hline Specimen & Surface roughness $\left(\mathrm{R}_{\mathrm{a}}\right)$ \\
\hline $\mathrm{Ti}$ & $0.79( \pm 0.03)$ \\
$\mathrm{HA}$ & $0.73( \pm 0.03)$ \\
$\mathrm{Ald}$ & $0.73( \pm 0.06)$ \\
\hline
\end{tabular}

Mean surface roughness of implant was not significantly different at $p<0.05$.

Table 3 Measured bone to implant contact in ROI (\%)

\begin{tabular}{lllll}
\hline & 3 weeks & \multicolumn{3}{c}{9 weeks } \\
\cline { 2 - 5 } Implants & Mean & SD & Mean & SD \\
\hline Ti & $29.2^{\mathrm{a}, \mathrm{A}}$ & 5.2 & $78.7^{\mathrm{B}}$ & 6.1 \\
$\mathrm{HA}$ & $63.4^{\mathrm{b}}$ & 18.2 & 85.9 & 12.4 \\
Ald & $88.6^{\mathrm{c}}$ & 4.6 & 90.2 & 2.9 \\
\hline
\end{tabular}

Means with different superscripts are significantly different at $p<0.05$.

Lower case letters indicate the difference between the implant materials with the same implantation periods.

Upper case letters indicate the difference between 3 and 9 weeks with the same materials.

implant surface. This revealed that uniform apatite coating could be deposited on the screw-type cylindrical Ti implant using the molecular precursor method.

XPS spectra for Ti and Ald implants are shown in Fig. 6 with the structural formulae of alendronate. N1s and $\mathrm{P} 2 \mathrm{p}$ peaks derived from immobilized alendronate were recognized at binding energies of $399.3 \mathrm{eV}$ and $133.8 \mathrm{eV}$, respectively. ${ }^{16,33)}$ Thus, the immobilization of alendronate to HA implant was confirmed.

Fig. 7 shows the SEM photographs of the surfaces of Ti, HA and Ald implants. There were no distinct differences of surface appearances among Ti, HA and Ald implants. Uniform apatite coating using the molecular precursor method was identified. The $\mathrm{Ra}$ value for each implant is shown in Table 1. No significant differences existed among Ti, HA and Ald implants ( $p>0.05$ ).

\section{Micro-CT images}

Typical micro-CT images of the maxillae are shown in Fig. 8. Implants were placed next to the second molar and slightly inclined in the distal direction because of insertion into the mesial root socket.

\section{Fluorescent labeling of new bone formation}

Typical CLSM images at 3 and 9 weeks after the implantation are shown in Fig. 9. At 3 weeks after implantation, more bone labeling was seen around the Ald implants (Fig. 9c) than around the Ti (Fig. 9a) and HA (Fig. 9b) implants. At 9 weeks after implantation, levels of bone labeling appeared to be similar among the three implants (Fig. 9 d, e, f). As green fluorochrome labeling
Table 2 Total length of calcein labels in ROI $\left(\mathrm{mm} / \mathrm{mm}^{2}\right)$ Means with different superscripts are significantly different at $p<0.05$.

\begin{tabular}{lllll}
\hline & 3 weeks & \multicolumn{3}{c}{9 weeks } \\
\cline { 2 - 5 } Implants & Mean & SD & Mean & SD \\
\hline Ti & $4.9^{\mathrm{a}}$ & 1.9 & 3.1 & 1.3 \\
HA & $7.8^{\mathrm{C}}$ & 1.2 & $2.9^{\mathrm{D}}$ & 0.9 \\
Ald & $10.3^{\mathrm{b}, \mathrm{E}}$ & 2.3 & $3.3^{\mathrm{F}}$ & 0.3 \\
\hline
\end{tabular}

Lower case letters indicate the difference between the implant materials with the same implantation periods. Upper case letters indicate the difference between 3 and 9 weeks with the same materials.

Table 4 Measured Bone mass in ROI (\%)

\begin{tabular}{lllll}
\hline & \multicolumn{2}{c}{3 weeks } & \multicolumn{3}{c}{9 weeks } \\
\hline Implants & Mean & SD & Mean & SD \\
\hline Ti & $41.0^{\mathrm{a}, \mathrm{A}}$ & 9.5 & $67.2^{\mathrm{d}, \mathrm{B}}$ & 4.5 \\
HA & $60.1^{\mathrm{b}}$ & 12.0 & $63.6^{\mathrm{d}}$ & 18.9 \\
Ald & $80.1^{\mathrm{c}, \mathrm{D}}$ & 3.5 & $88.1^{\mathrm{e}, \mathrm{E}}$ & 0.8 \\
\hline
\end{tabular}

Means with different superscripts are significantly different at $p<0.05$.

Lower case letters indicate the difference between the implant materials with the same implantation periods.

Upper case letters indicate the difference between 3 and 9 weeks with the same materials.

due to calcein administration was more clearly visible than alizarin red labeling, we assessed new bone formation by the total length of calcein labeling in the ROI (Table 2). At 3 weeks after the implantation, the Ald implants had a greater value than the HA and $\mathrm{Ti}$ implants, although the difference was only significant from the Ti implants ( $\mathrm{p}=0.0106)$. At 9 weeks, there were no significant differences among the three types of implant. Calcein labeling significantly decreased from 3 weeks to 9 weeks for the HA and Ald implants.

\section{Histology evaluation}

The histological appearances of bone formation around the three implants at 3 weeks after the implantation are shown in Fig. 10. Bone responses to the different implants were clearly different. The degree of bone mass around the HA implants appeared to be greater than around the Ti implants, and the Ald implants showed more bone mass than the Ti and HA implants.

After 9 weeks of implantation, overall trabecular bone responses to the different implants were similar, as shown in Fig. 10.

The results of the measurements of BIC and BM are shown in Tables 3 and 4 . At 3 weeks, significant differences in BIC existed among the three different implants $(\mathrm{p}<0.05)$. The Ald implants showed significantly higher BIC $(\mathrm{p}<0.05)$. At 9 weeks, there were 
Yuki Raita et al.: Bone Formation around Alendronate-Immobilized Titanium Implant

no significant differences in BIC among the three different implants. BIC of Ti significantly increased from 3 weeks to 9 weeks $(\mathrm{p}<0.05)$. For the HA and Ald implants, there were no significant differences in BIC between 9 weeks and 3 weeks $(\mathrm{p}>0.05)$.

For BM at 3 weeks after the implantation, there were significant differences among the three different implants $(\mathrm{p}<0.05)$. The Ald implants showed the highest BM $(\mathrm{p}<0.05)$. At 9 weeks after the implantation, no significant differences existed between Ti and HA ( $p>0.05)$, and Ald implants also showed the highest BM $(p<0.05)$. The Ti and Ald implants at 9 weeks showed significantly higher $\mathrm{BM}$ than those at 3 weeks $(\mathrm{p}<0.05)$. For the HA implants, there was no significant difference between 9 weeks and 3 weeks $(\mathrm{p}>0.05)$.

\section{Discussion}

This study demonstrated the enhancement of local bone formation around alendronate-immobilized titanium implants in a rat model.

It was reported that subcutaneous injection of BP during the implantation period was effective for accelerating the bone healing process and improving implant fixation by inhibiting osteolysis. ${ }^{34-}$ 36) However, undesirable side effects of bisphosphonate-related osteonecrosis of the jaw (BRONJ) were claimed. BRONJ is characterized by the unexpected appearance of necrotic bone in the oral cavity and oncologic patients receiving high doses of BP intravenously are at high risk for its development. ${ }^{37-39)}$ Osteonecrosis can develop spontaneously after an invasive surgical procedure such as dental extraction. Janovskáa ${ }^{40}$ reported that BRONJ is a result of tooth extraction in about $60 \%$ of patients. Thus, instead of systemic application, local application of BPs seems to be safer and more useful for improving the bone healing response without causing BRONJ.

Alendronate was immobilized onto apatite-coated titanium implants. As an apatite-coating method, the molecular precursor method was employed. Several methods for apatite coating have been proposed. For example, physical vapor deposition techniques such as plasma spraying or magnetron sputtering have been mainly applied. ${ }^{41)}$ The molecular precursor method is a new wet process for coating thin apatite layers onto titanium. An alcoholic solution of Ca-EDTA complex and phosphate compounds is used as the molecular precursor solution. The advantages of this method are its simplicity and that the apatite coating can be deposited onto titanium implants of any shape. A three-dimensional titanium fiber mesh could previously be coated with thin apatite using the molecular precursor method, not only on the surface but also on the inside of a fiber mesh. ${ }^{42)}$ The present study also revealed that the molecular precursor method could deposit a uniform thin apatite coating onto a screw-type titanium implant.

In the present study, alendronate was used as a BP. Alendronate is a nitrogen-containing BP known as a second-generation BP, which is more potent than pamidronate. ${ }^{9)}$ The immobilization of alendronate onto apatite-coated implant was confirmed by XPS measurement. The presence of a Ti2 $p$ peak indicated that the titanium surface was not completely covered with alendronate.

It is well known that the surface roughness of a dental implant remarkably influences bone response. ${ }^{1,2)}$ In this study, the levels of surface roughness of the HA and Ald implants were almost the same as that of the Ti implants. Thus, the influence of surface roughness on bone response could be ruled out. Only the chemical condition of the implant surface influenced the bone healing process.

It was revealed that alendronate immobilization promoted new bone formation at an early stage of the bone healing process. As well-known effects, it is presumed that immobilized alendronate regulates apatite crystal growth and dissolution and inhibits osteolysis in the vicinity of implants by reacting directly with osteoclasts and osteoblasts.

BP may also act through the modulation of osteoclastosteoblast interaction. Recent findings suggest that BPs are not only potent inhibitors of osteoclastic bone resorption, but also have direct effects on osteoblasts. Some researchers reported that alendronate enhanced the osteogenic differentiation of osteoblasts and bone marrow mesenchymal stem cells. ${ }^{43,44)}$ Moon et al. ${ }^{45)}$ demonstrated that alendronate-immobilized titanium implant surface showed enhancement of osteoblast function as well as osteoclastic inhibition. They immobilized alendronate to a heparingrafted titanium surface. It has been shown that local treatment with alendronate enhanced bone formation by stimulating the proliferation and differentiation of bone-forming cells adjacent to the bone surfaces as well as inhibiting osteoclastic resorption activity in a tooth replantation model. ${ }^{46)}$ Thus, it was suggested that alendronate has a dual function in the improvement in osteoblast functions and the inhibition of osteoclast differentiation.

Previous studies by Still et al. ${ }^{47)}$ reported that lower concentrations $\left(10^{-8}-10^{-5} \mathrm{M}\right)$ of alendronate, risedronate and zolendronate enhanced the proliferation of human trabecular bone cells, osteoblast-like cells and bone marrow stromal cells. Gao et al. ${ }^{20)}$ reported that the concentrations of $\mathrm{N}$-containing BPs such as zoledronate, pamidronate and ibandronate released in vitro from the BP-coated implants were estimated to reach 0.3-0.4 $\mu \mathrm{M}$ in 24 $\mathrm{h}$ and then decline gradually. McKenzie et al. ${ }^{48)}$ also investigated the elution of zolendronic acid from a porous apatite-coated tantalum implant using a radio-labeling technique and claimed that the elution of zoledronic acids mainly localized in peri-implant bone, and peri-implant bone formation was strongly confined to the immediate space around the implant border. They also insisted that remote skeletal sites are probably distant from a boneremodeling standpoint. In contrast, Bodde et al. ${ }^{49)}$ reported that alendronate and omeprazole did not result in better bone healing 
when incorporated into bioactive bone cement. Since we did not monitor the release of alendronate after implantation, the local concentrations of alendronate around the implants are unknown. It is speculated that their negative response was due to excessive doses of alendronate and early burst release from the bone cement. Since we did not monitor the release of alendronate after implantation, the local concentrations of alendronate around the implants are unknown. However, it is presumed that the present results are due to a lower concentration of alendronate release from the surfaces of Ald implants and Ald implants may stimulate bone formation around them. The influence of immobilized and released amounts of alendronate on the bone response should be subjected to further investigation.

Screw-type implants were inserted into the sockets of mesial roots of the extracted maxillary first molars after the enlargement of the socket of the mesial roots. A preliminary experiment revealed that, when implants were inserted into the sockets of another root of the extracted maxillary first molar after the enlargement, most of them showed loosening at an early stage of implantation. This was due to the downward growth of peri-implant tissue. Insertion into the socket of mesial root provided stable placement of the implants.

Calcein administration provided clear green fluorochrome labeling and also proved early bone formation during the healing process around Ald implants. However, labeling by alizarin red could not be clearly recognized. It is presumed that the administered dose was insufficient for bone labeling. Administration of a higher dose of alizarin red or another appropriate labeling agent should be attempted in additional experiments.

In conclusion, alendronate-immobilized implants are beneficial for promoting the bone healing process and enhancing new bone formation at an early stage of implantation. Gao et al. ${ }^{20)}$ reported that immobilized BPs on apatite-coated implants have positive effects on implant fixation in osteoporotic tibia bone. The efficacy of alendronate immobilization onto osteoporotic maxillary bone should be explored at the next stage of our experiments.

\section{Acknowledgements}

We are grateful Assistant Professor Dr. Tetsuo Umegaki and Associate Professor Dr. Takeshi Toyama, Department of Materials and Apliced Chemistry, College of Science and Technology, Nihon University for their help for the measurements of X-ray photoelectron spectroscopy.

\section{References}

1. Wennerberg A and Albrektsson T. Effects of titanium surface topography on bone integration: A systematic review. Clin Oral Implants Res 20 (S4): 172-184, 2009
2. Wennerberg A and Albrektsson T. On implant surfaces: A review of current knowledge and opinions. Int J Oral Maxillofac Implants 25: 63-74, 2010

3. Bhola R, Su F and Krull CE. Functionalization of titanium based metallic biomaterials for implant applications. J Mater Sci Mater Med 22: 1147-1159, 2011

4. Yoshida E, Yoshimura Y, Uo M, Yoshinari M and Hayakawa $\mathrm{T}$. Influence of nanometer smoothness and fibronectin immobilization of titanium surface on MC3T3-E1 cell behavior. J Biomed Mater Res A 100: 1556-1564, 2012

5. Mundy GR and Yoneda T. Bisphosphonates as anticancer drugs. N Engl J Med 339: 398-400, 1998

6. Berenson JR, Rosen LS, Howell A, Porter L, Coleman RE, Morley W, Dreicer R, Kuross SA, Lipton A and Seaman JJ. Zoledronic acid reduces skeletal-related events in patients with osteolytic metastases. Cancer 91: 1191-1200, 2001

7. Reid IR, Miller P, Lyles K, Fraser W, Brown JP, Saidi Y, Mesenbrink P, Su G, Pak J, Zelenakas K, Luchi M, Richardson $\mathrm{P}$ and Hosking D. Comparison of a single infusion of zoledronic acid with risedronate for Paget's disease. N Engl J Med 353: 898-908, 2005

8. Fleisch H. Bisphosphonates: Mechanisms of action. Endocr Rev 19: 80-100, 1998

9. Russell RG. Bisphosphonates: mode of action and pharmacology. Pediatrics 119 (S2): 150-162, 2007

10. Benford HL, Frith JC, Auriola S, Mönkkönen J and Rogers MJ. Farnesol and geranylgeraniol prevent activation of caspases by aminobisphosphonates: biochemical evidence for two distinct pharmacological classes of bisphosphonate drugs. Mol Pharmacol 56: 131-140, 1999

11. Luckman SP, Hughes DE, Coxon FP, Graham R, Russell G and Rogers MJ. Nitrogen-containing bisphosphonates inhibit the mevalonate pathway and prevent post-translational prenylation of GTP-binding proteins, including Ras. J Bone Miner Res 13: 581-589, 1998

12. Frith JC, Mönkkönen J, Blackburn GM, Russell RG and Rogers MJ. Clodronate and liposome-encapsulated clodronate are metabolized to a toxic ATP analog, adenosine 5'-(beta, gamma-dichloromethylene) triphosphate, by mammalian cells in vitro. J Bone Miner Res 12: 1358-1367, 1997

13. Hayakawa T, Furuya N, Yasuoka S, Katoh T and Fukushima T. Computational analysis of bisphosphonates and bisphosphonate/calcium complexes. J Oral Tissue Eng 8:107114,2010

14. Wermelin K, Suska F, Tengvall P, Thomsen P and Aspenberg P. Stainless steel screws coated with bisphosphonates gave stronger fixation and more surrounding bone. Histomorphometry in rats. Bone 42: 365-371, 2008

15. Andersson T, Agholme F, Aspenberg P and Tengvall P. Surface 
Yuki Raita et al.: Bone Formation around Alendronate-Immobilized Titanium Implant

immobilized zoledronate improves screw fixation in rat bone: a new method for the coating of metal implants. J Mater Sci Mater Med 21: 3029-3037, 2010

16. Yoshinari M, Oda Y, Ueki H and Yokose S. Immobilization of bisphosphonates on surface modified titanium. Biomaterials 22: 709-715. 2001

17. Kajiwara H, Yamaza T, Yoshinari M, Goto T, Iyama S, Atsuta I, Kido MA and Tanaka T. The bisphosphonate pamidronate on the surface of titanium stimulates bone formation around tibial implants in rats. Biomaterials 26: 581-587, 2005

18. Tanzer M, Karabasz D, Krygier JJ, Cohen R and Bobyn JD. The Otto Aufranc Award: bone augmentation around and within porous implants by local bisphosphonate elution. Clin Orthop Relat Res 441: 30-39, 2005

19. Niu S, Cao X, Zhang Y, Zhu Q, Zhu J. The inhibitory effect of alendronate-hydroxyapatite composite coating on wear debris-induced peri-implant high bone turnover. J Surg Res 179: 107-115, 2013

20. Gao Y, Zou S, Liu X, Bao C and Hu J. The effect of surface immobilized bisphosphonates on the fixation of hydroxyapatite-coated titanium implants in ovariectomized rats. Biomaterials 30: 1790-1796, 2009

21. Listgarten MA. Soft and hard tissue response to endosseous dental implants. Anat Rec 245: 410-425, 1996

22. Masuda T, Yliheikkilä PK, Felton DA and Cooper LF. Generalizations regarding the process and phenomenon of osseointegration. Part I. In vivo studies. Int J Oral Maxillofac Implants 13: 17-29, 1998

23. Yoshinari M, Oda Y, Inoue T, Matsuzaka K and Shimono M. Bone response to calcium phosphate-coated and bisphosphonate-immobilized titanium implants. Biomaterials 23: 2879-2885, 2002

24. Meraw SJ, Reeve CM and Wollan PC. Use of alendronate in peri-implant defect regeneration. J Periodontol 70: 151-158, 1999

25. Futami T, Fujii N, Ohnishi H, Taguchi N, Kusakari H, Ohshima $\mathrm{H}$ and Maeda T. Tissue response to titanium implants in the rat maxilla: ultrastructural and histochemical observations of the bone-titanium interface. J Periodontol 71: 287-298, 2000

26. Ikeda H, Yamaza T, Yoshinari M, Ohsaki Y, Ayukawa Y, Kido MA, Inoue T, Shimono M, Koyano K and Tanaka T. Ultrastructural and immunoelectron microscopic studies of the peri-implant epithelium-implant (Ti-6Al-4V) interface of rat maxilla. J Periodontol 71: 961-973, 2000

27. Komatsu K, Shimada A, Shibata T, Shimoda S, Oida S, Kawasaki $\mathrm{K}$ and Nifuji A.Long-term effects of local pretreatment with alendronate on healing of replanted rat teeth. J Periodontal Res 43: 194-200, 2008

28. Takahashi K, Hayakawa T, Yoshinari M, Hara H, Mochizuki
C, Sato M and Nemoto K. Molecular precursor method for thin calcium phosphate coating on titanium. Thin Solid Films 484: 1-9, 2005

29. Hayakawa T, Ametani A, Kuboki Y and Sato M. Thin carbonate-containing apatite coating of titanium web using molecular precursor method under oxygen gas introduction. J Oral Tissue Eng 6: 201-210, 2009

30. König JB, Beck TJ, Kappert HF, Kappert CC and Masuko TS. A study of different calcification areas in newly formed bone 8 weeks after insertion of dental implants in rabbit tibias. Ann Anat 180: 471-475, 1998

31. Donath K and Breuner G. A method for the study of undecalcified bones and teeth with attached soft tissues. The Säge-Schliff (sawing and grinding) technique. J Oral Pathol 11: 318-326, 1982

32. Recker RR, Kimmel DB, Dempster D, Weinstein RS, Wronski $\mathrm{TJ}$ and Burr DB. Issues in modern bone histomorphometry. Bone 49: 955-964, 2011

33. Wagner CD, Riggs WM, Davis LE, Moulder JF and Muilenberg GE. Handbook of X-ray photoelectron spectroscopy. Perkin-Elmer Corp, 1979

34 von Knoch F, Eckhardt C, Alabre CI, Schneider E, Rubash HE and Shanbhag AS. Anabolic effects of bisphosphonates on peri-implant bone stock. Biomaterials 28: 3549-3559, 2007

35. Eberhardt C, Habermann B, Müller S, Schwarz M, Bauss F and Kurth $\mathrm{AH}$. The bisphosphonate ibandronate accelerates osseointegration of hydroxyapatite-coated cementless implants in an animal model. J Orthop Sci 12: 61-66, 2007

36. Kim JH, Park YB, Li Z, Shim JS, Moon HS, Jung HS and Chung MK. Effect of alendronate on healing of extraction sockets and healing around implants. Oral Dis 17: 705-711, 2011

37. Marx RE, Cillo JE Jr and Ulloa JJ. Oral bisphosphonateinduced osteonecrosis: risk factors, prediction of risk using serum CTX testing, prevention, and treatment. J Oral Maxillofac Surg 65: 2397-2410, 2007

38. Migliorati CA, Siegel MA and Elting LS. Bisphosphonateassociated osteonecrosis: a long-term complication of bisphosphonate treatment. Lancet Oncol 7: 508-514, 2006

39. Migliorati CA, Epstein JB, Abt E and Berenson JR. Osteonecrosis of the jaw and bisphosphonates in cancer: a narrative review. Nat Rev Endocrinol 7: 34-42, 2011

40. Janovská Z. Bisphosphonate-related osteonecrosis of the jaws. A severe side effect of bisphosphonate therapy. Acta Medica (Hradec Kralove) 55: 111-115, 2012

41. Ong JL and Chan DC. Hydroxyapatite and their use as coatings in dental implants: a review. Crit Rev Biomed Eng 28: 667-707, 2000

42. Hayakawa T, Takahashi K, Okada H, Yoshinari M, Hara H, 
Mochizuki C, Yamamoto $\mathrm{H}$ and Sato M. Effect of thin carbonate-containing apatite (CA) coating of titanium fiber mesh on trabecular bone response. J Mater Sci Mater Med 19: 2087-2096, 2008

43. Inoue Y, Hisa I, Seino S and Kaji H. Alendronate induces mineralization in mouse osteoblastic MC3T3-E1 cells: regulation of mineralization-related genes. Exp Clin Endocrinol Diabetes 118: 719-723, 2010

44. Kim HK, Kim JH, Abbas AA and Yoon TR. Alendronate enhances osteogenic differentiation of bone marrow stromal cells: a preliminary study. Clin Orthop Relat Res 467: 31213128, 2009

45. Moon HJ, Yun YP, Han CW, Kim MS, Kim SE, Bae MS, Kim GT, Choi YS, Hwang EH, Lee JW, Lee JM, Lee CH, Kim DS and Kwon IK. Effect of heparin and alendronate coating on titanium surfaces on inhibition of osteoclast and enhancement of osteoblast function. Biochem Biophys Res Commun 413: 194-200, 2011
46. Komatsu K, Shimada A, Shibata T, Wada S, Ideno H, Nakashima K, Amizuka N, Noda M and Nifuji A. Alendronate promotes bone formation by inhibiting protein prenylation in osteoblasts in rat tooth replantation model. J Endocrinol doi: 10.1530/JOE-13-0040, 2013

47. Still K, Phipps RJ and Scutt A. Effects of risedronate, alendronate, and etidronate on the viability and activity of rat bone marrow stromal cells in vitro. Calcif Tissue Int 72: 143-150, 2003

48. McKenzie K, Dennis Bobyn J, Roberts J, Karabasz D amd Tanzer M. Bisphosphonate remains highly localized after elution from porous implants. Clin Orthop Relat Res 469: 514-522, 2011

49. Bodde EW, Kowalski RS, Spauwen PH and Jansen JA. No increased bone formation around alendronate or omeprazole loaded bioactive bone cements in a femoral defect. Tissue Eng Part A 14: 29-39, 2008 